\title{
OUTLINE OF A THEORY OF ORGANIC CHEMISTRY FOUNDED ON THE LAW OF ENTROPY.'
}

BY ARTHUR MikHAFL.

Received frime 27 , tolo.

There appears to be no generalization in science more firmly established than the second law of thermodynamics, which demands that every spontaneous chemical change shall be accompanied by an increase of entropy, and that the system shall endeavor to realize this increase to its maximum extent.

Since the law of entropy represents the fundamental principle, underlying and regulating all chemical phenomena occurring in nature, it must necessarily be the correct scientific basis for the theory of organic chemistry. But it is a curious fact that there has been as yet little attempt to use this basic chemical principle in connection with organic theory; this theory has been developed along lines so mechanical in their character that it is perhaps no exaggeration to speak of them as essentially pictorial. This unilateral, mechanical development is due largely to the interpretation of the phenomenon called valency; and, if we are to incorporate the law of entropy into chemical theory, it is here that our theoretical conceptions will require a radical modification.

Before entering a discussion of the subject of valency, we shall mention a conception of the chemical genesis of matter, since it prepares the way for the theoretical views which follow. A simple hypothesis is to assume that cosmos was originally made up of two kinds of matter, which were the carriers of two kinds of chemical energy, ${ }^{2}$ and that the temperature of the system was inconceivably low. Chemical energy, as it now appears to us, exists in two conditions. One of these is freely and perfectly convertible into less active chemical energy and into various forms of physical energy; and this less active chemical energy can be reconverted into the active form only partially and then with comparative difficulty. We shall designate the active form free, the relatively inactive form, bound chemical energy, ${ }^{3}$ and, as the transformations of chemical energy must have obeyed the law of entropy since the begiruning of cosmos, the original corpuscles were exclusively carriers of free chemical energy, and the accumulation of bound chemical energy and the various forms of physical energy now existing have been gradually evolved from it.

1 Address delivered at the Second Decennial Celebration of Clark University, Worcester, Mass., September 15, I909.

${ }^{2}$ To distinguish between them they will be called positive and negative, but this does not imply any connection with positive and negative electricity.

${ }^{3}$ The terms free and bound chemical energy, as here 1sed, are not to be confused with the terms free and bound energy as used in physical chemistry, with which they are not identical. 
The permanence of the law of entropy justifies the conclusion that the chemical relations which existed between the corpuscles at the beginning were similar to those which now exist between the atoms and the molecules. We may, therefore, assume that the free chemical energy of unlike and like corpuscles united to form aggregations in which the corpuscles were held together by bound chemical energy. At first the chemical evolution of matter must have been accompanied by an enormous rise of temperature, but later, owing to the decreasing amount of free chemical energy in the cosmical system, a period must have come when the loss of heat through radiation was greater than its formation, and then the temperature of the system must have begun to decrease. We may assume, too, that the atoms of those elements, the molecules of which now show the greatest stability toward heat were formed first and during the hottest period of cosmical evolution. Hence, the atoms of hydrogen, and those of the non-metals, with small atomic weight, represent the earliest forms of atomic matter.

If we suppose that in the formation of the atoms of certain elements the free chemical energy of the corpuscles was very largely converted into bound chemical energy and heat, their atoms would be extremely inert toward other atoms and incapable of uniting with each other. Such elementary matter is represented by the so-called noble gases, in the atoms of which the relation of free corpuscular to free atomic chemical energy is analogous to that of free atomic to free molecular chemical energy in the atom and molecule of nitrogen. Further, if we suppose that thermic, or other conditions, toward the end of the corpuscular period of chemical evolution no longer permitted a sufficient conversion of free into bound chemical energy, we get a glimpse into the genesis of radioactive matter, the atoms of which contain so much free corpuscular chemical energy that they represent a reversible system and are, therefore, gradually breaking down into smaller parts, which then rearrange according to the changed conditions of cosmos.

Kekule," in his memorable paper, "Ueber die Constitution und die Metamorphosen der chemischen Verbindungen," assumed that the first phase in chemical union consists in molecules attracting each other through their chemical affinity, and that a sort of loosely joined, larger molecule is thus formed. It is obvious that the formation of this "Kekule polymolecule"' is due to the attraction between the free chemical energy in the constituent molecules, and that it proceeds with the conversion of more or less free into bound chemical energy and heatthe extent of this change determining its stability.

Let us represent the free chemical energy in an atom by a point 1 Ann., I06, 14I.

${ }^{2}$ Michael: Ber., 34, 4028; 39, 2140, 2570. Am. Chem. J., 39, 3; 4I, 120. 
and the bound by a line, and let the number of the points and the length of the lines be a rough indication of the charres in the energy values occurring during the reaction. If we assume that the energies of unlike character in a molecule of sodium and of chlorine are approximately equal in value, we may represent the energy relations in sodium and chlorine by

$$
\begin{array}{ccc}
\vdots & \vdots & \vdots \\
\mathrm{Na}-\mathrm{Na} & \mathrm{Cl}-\mathrm{C} 1
\end{array}
$$

and the "polymolecule," representing the first phase in their interaction, by

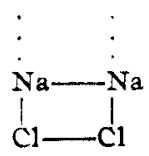

which indicates that some of the free has been converted into bound chemical energy. The free chemical energies of unlike character would then strive to neutralize each other as completely as possible, a phase of the reaction that may be represented by

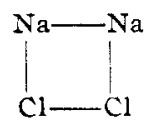

and then, certainly facilitated by the enormous "internal maximum heat of reaction," the bound chemical energies between $\mathrm{Na}$ and $\mathrm{Na}$ and $\mathrm{Cl}$ and $\mathrm{Cl}$ would be converted into bound chemical energy between $\mathrm{Na}$ and $\mathrm{Cl}$ and $\mathrm{Na}$ and $\mathrm{Cl}$; finally, to realize a phase which may be represented by

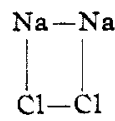

At this point, the bound chemical energy between the atoms of like nature may be inadequate to hold them together, and the complex would then break down into two molecules of $\mathrm{NaCl} .^{2}$

What happens if we substitute magnesium in the place of sodium; that is, an element the atom of which contains much less positive energy? The formation of a "polymolecule," then the conversion of the free chemical energy in the metallic and non-metallic atoms into bound between metal and halogen; but, although the energy in the sodium molecule suffices to neutralize that in the chlorine to an extent that the complex breaks down into two molecules, that in the much less positive mag-

'Wohl, Ber., 40, 229o. That part of the free and bound chemicul energy is converted into heat has not been indicated.

${ }^{2}$ The energies in two unlike atoms are never capable of exactly neutralizing each other, so that a certain content of free chemical energy is invariably present in the atoms of every molecule. 
nesium molecule is insufficient to convert enough of the bound energy between the chlorine atoms into bound energy between metal and halogens, therefore the latter atoms separate. On the other hand, the greater energy in the chlorine atoms is capable of using up that in the magnesium to an extent that these fall apart. In magnesium chloride, therefore, the halogen has a considerably greater content of free chemical energy than it has in sodium chloride, and bound chemical energy exists not only between it and the metal, but between the chlorine atoms. We may represent these relations by:

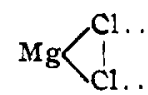

While the energy in a molecule of magnesium is not sufficient to separate the chlorine atoms, it obviously may be able to do so with the less negative oxygen, and, if the opposite energies in magnesium and oxygen approximately neutralize each other, two molecules of magnesium oxide should be formed. But, if we take oxygen and a metal with considerably more positive energy than magnesium, say lithium, the oxygen is not able to separate the metallic atoms, while the latter can separate the oxygen atoms, thus leading to the formation of $\mathrm{Li}_{2} \mathrm{O}$, in which the $\mathrm{Li}$ atoms are held together by bound chemical energy. The valency of an element, according to this interpretation, represents the resultant of the intramolecular chemical forces acting on the atom in terms of bound chemical energy, whether the action takes place directly, that is through direct union of the atoms or through space; or indirectly, that is, through other atoms. In as far as the free chemical energy in the atoms is not so converted into bound chemical energy, it will be able to exert readily a chemical attraction for such other atoms, either in the same or other molecules, for which it shows a chemical affinity.

Although a spontaneous chemical change can proceed only with increase of entropy, the increment depends on free chemical energy and chemical affinity existing between those atoms, which in the reaction enter into direct union with each other. The atoms in a molecule are held together solely by bound chemical energy and, if their chemical nature is such that their free chemical energy has very largely disappeared in the formation of the molecule, the substance must be chemically inert; if not, it will be more or less chemically active. Thus, the well neutralized condition of $\mathrm{NaCl}$ and $\mathrm{Al}_{2} \mathrm{O}_{3}$, the superabundant positive energy in $\mathrm{Na}_{2} \mathrm{O}$, and the negative in $\mathrm{AlCl}_{3}$, is reflected in the properties of those substances.

Let us suppose that we could isolate and experiment with elements other than the noble gases in atomic condition, and could pre. vent the formation of molecules by the union of like, but not of unlike, atoms. In such a system free chemical energy would be amply present 
and chemical union would therefore depend alone on the affinity relations of the atoms. Moreover, if an isomeric substance could be formed, it would be that particular isomer which would represent the maximum entropy of the system under the prevailing conditions.

For instance, the present structure theory indicates the existence of two isomeric cyanogen chlorides, i. e., $\mathrm{ClNC}$ and $\mathrm{ClCN}$, but leaves us entirely in doubt why only one is known. So great is the uncertainty in regard to its constitution that this has long been a subject of active discussion and investigation. ${ }^{1}$ Chlorine, nitrogen and carbon in atomic condition would possess ample free chemical energy for union and the question which isomer would be formed would depend on the increase of entropy connected with the affinity relations of $\mathrm{Cl}$ for $\mathrm{N}$ and for $\mathrm{C}$. Since we know that the affinity between $\mathrm{Cl}$ and $\mathrm{N}$ is exceedingly slight, and that between $\mathrm{Cl}$ and $\mathrm{C}$ is large, it is absolutely certain that the isomer in which the halogen is united directly to the $\mathrm{C}, i . e_{\text {., }} \mathrm{ClCN}$, would be the direct product. Furthermore, a consideration of the energetic conditions enables us to predict the properties of the isomeric form ( $\mathrm{ClNC}$ ); it could exist only at a very low temperature and under ordinary condition the rearrangement $\mathrm{ClNC} \rightarrow \mathrm{ClCN}$ would occur so quickly, and with such a great increase of heat that the substance would be a violent explosive. ${ }^{2}$ The matter we actually deal with is, however, in a molectular condition and all chemical changes that do not proceed solely through expenditure of free chemical energy involve an expenditure of energy due to overcoming bound chemical energy between atoms in the molecule. Chemical action is dependent, therefore, on a third factor, which constitutes a chemical hindrance, and it can proceed spontaneously only when the increase of entropy due to changes of free chemical energy and affinity is greater than the expenditure of energy necessary to overcome the chemical hindrance. That is, when the value of the equation: chemical affinity plus free chemical energy divided by chemical hindrance, is positive.

To ascertain quantitative values for the various factors that determine an organic reaction is at present impossible, but it is of the greatest importance for the development of organic theory to be able to connect

1 See Michael and Hibbert, Ann., 364, 69.

2 It is evident that the content of free chemical energy in $\mathrm{ClNC}$ would be vastly greater than that in $\mathrm{ClCN}$, which implies a better condition of intramolecular neutraiization of the chemical forces of the atoms in the latter structure. Since such chemical neutralization proceeds with increase of entropy, we may substitute chemical neutralization in the place of entropy in the second law of thermodynamics. Further, we may apply the Carnot principle to the activity of free chemical energy of unlike kinds, and conclude that the increase of entropy will be greatest when the chemical forces are able to neutralize each other exactly. This law of chemical neutralization has the advantage over that of entropy in a much wider application to organic reactions (Michael, J. prakt. Chem., [2] 60, 293; 68, 489. Ber., 38, 23). 
changes in these values with modifications in structure. This done, we shall then be able to predict relative changes in the factors that contribute to the entropy values and thus be able to understand and explain organic reactions to a degree at present impossible.

What are the properties of carbon on which the existence of this wonderful and intricate organic world mainly depend? First, its capacity to polymerize, to form stable chains of astonishing length; second, the extreme sensitiveness of its properties to the influence of other elements, ${ }^{1}$ which is shared in a like degree only by hydrogen, and which has been called its "chemical plasticity"; 2 and third, its high valence combined with its marked affinity for hydrogen and for most of the non-metals, to form more or less stable derivatives.

The first of these properties stands clearly in a close relation to the position of the element in the periodic system. In the halogen group, the tendency to form greater than diatomic molecules is not shown, with the exception perhaps of iodine; in the oxygen group it is shown by that element, but in a far greater degree by the other members. From analogy, a similar tendency to form large molecules by conversion of free into bound chemical energy should be expected in passing from oxygen to nitrogen, but the latter element acts anomalously, although in the formation of its diatomic molecule its free is converted into bound chemical energy to a remarkable extent.

The next member of this group, phosphorus, shows a marked capacity to polymerize to large molecules, and the conversion of ordinary into red phosphorus, which is accompanied by the evolution of only ig calories, is one of the most salient illustrations in chemistry of how a change of free into bound chemical energy will radically change the properties of a substance. The very existence of organic life depends on carbon not sharing with nitrogen the property of polymerizing to a diatomic molecule, which is poor in free chemical energy. The actual change in passing from $\mathrm{N}$ to $\mathrm{C}$ is similar to that in going from $\mathrm{N}$ to $\mathrm{P}$, but it is in a degree much more highly developed, and carbon represents among elements the greatest capability to use the free chemical energy in its atom to form molecules containing a large number of atoms. The midway position of carbon in the second series of the periodic system indicates that there is an approximate balance of positive and negative corpuscles in the make-up of its atom. And, as the polymerizing capacity of non-metallic atoms increases, generally speaking, with a tendency toward this constitution of their atoms, it seems reasonable to connect this all-important property of the carbon atom with its corpuscular composition.

A relation which is hardly less important for organic theory than the

1 Van't Hoff, Ansichten uber organische Chem., I, 280 ; II, 242.

2 Michael, J. prakt. Chem. [2], 60, 325. 
foregoing, is to what extent the polymerizing power of carbon is modified by the presence of other elements in the molecule, and the influence which they exert on the affinity of carbon for hydrogen and for nonmetals. Without exception, every element joined to carbon decreases its polymerizing capacity, $i . c$, its affinity for itself, and the influence is in the order, $\mathrm{H}$, halogen, $\mathrm{N}, \mathrm{S}$ and $\mathrm{O}$. To the intuence of the last element carbon is so exceedingly sensitive that, through direct union with a single atom of oxygen, the enormous combining capacity of the carbon atom for itself is completely destroyed.

Notwithstanding the considerable content of free chemical energy in the atoms of $\mathrm{CO}$, this substance shows practically no tendency to polymerize, but the characteristic property of carbon reappears at once, when the influence of oxygen is neutralized by the presence of other elements. Thus, the action of potassium on CO leads not to COK, but to a polymerized product, derived from benzene.

Not only does $\mathrm{O}$ decrease the affinity of $\mathrm{C}$ for $\mathrm{C}$, but of $\mathrm{C}$ for $\mathrm{H}$ and for any non-metal to which carbon may be joined, whether the atoms are directly or indirectly joined. This is true to a degree directly proportionate to the extent of such negative influences acting on the atoms. ${ }^{1}$ The capacity of hydrogen to decrease the affinity of carbon for carbon is far less than that of oxygen, but it plays, nevertheless, an important role in many organic reactions. Thus, the pinacone $\longrightarrow$ pinacoline rearrangement: $\left(\mathrm{H}_{3} \mathrm{C}\right)_{2}=\mathrm{C}(\mathrm{OH})-(\mathrm{HO}) \mathrm{C}=\left(\mathrm{CH}_{3}\right)_{2} \rightarrow\left(\mathrm{CH}_{3}\right)_{3} \equiv$ $\mathrm{C}-\mathrm{CO}-\mathrm{CH}_{3}+\mathrm{H}_{2} \mathrm{O}$, takes place on boiling with dilute mineral acid, and the

${ }^{1}$ Michael, J. prakt. Chom., 37, 473;60, 286. Ber., 38, 28, 3221. The writer is unaware of any facts in organic chemistry which are not strictly in accordance with the above stated rule. W. A. Noyes ('This Journal, 3I, I3TI) believes that the greater instability of acetoacetic acid $\left(\mathrm{CH}_{3} \mathrm{COCH}_{2} \mathrm{CO}_{2} \mathrm{H}\right)$ over pyrotartaric acid $\left(\mathrm{CH}_{3} \mathrm{COCO}{ }_{2} \mathrm{H}\right)$ "is some slight indication that the separation of the carbon atoms is ionic in character, taking place more readily when there is a greater contrast between the atoms united together." In the first-named acid, the group $\mathrm{C}-\mathrm{CO}_{2} \mathrm{H}$ is under the influence of $\mathrm{H}_{2}$ and a negative, acidic radical $\left(\mathrm{CH}_{8} \mathrm{CO}\right)$, in the second under a positive radical $\left(\mathrm{CH}_{3}\right)$ and $\mathrm{O}$ and it is quite in agreement with the above rule that acetoacetic acid splits off $\mathrm{CO}_{2}$ much more readily than pyrotartaric acid. The writer, also, knows of no satisfactory evidence in favor of the view that any strictly organic reaction is ionic in character (see Michael, Ber., 38, 29; Am. Chem. J., 43, 322; Michael and Hibbert, Ber., $\left.3^{\mathrm{I}}, \mathrm{IOgO}\right)$; or of any facts that are more easily understood than otherwise by such an assumption. The formation of ethyl chloride from ethyl alcohol and phosphorus pentachloride, while phenol gives partly chlorobenzene, partly phenyl phosphate, is mentioned by Noyes (loc. cit., 1370) as confirming this view. However, when we consider that the chemical hindrance to the formation of a chloride, $i . e$, the energy necessary to separate hydroxyl irom the hydrocarbon radical, is much greater with phenol than with ethyl alcohol, it is obvious that such assumptions as that phenol can ionize to the phenyl and hydroxyl group, and that ethyl alcohol can ionize to ethyl and hydroxyl, do not contribute in any way to make the subject more clear. 
reaction apparently should lead, with loss of water, to the formation of tetramethylethylene oxide.

This compound contains a three-membered, cyclic chain, which is formed under considerable tension, and, besides, a large number (12) of hydrogen atoms, exerting in a very important position (3) their positive influence on the cyclic carbons. Such a structure cannot represent a very stable substance. On the one hand, there is considerable tension, representing energy in a potential condition; on the other, an extremely insufficient, intramolecular chemical neutralization of the positive by the negative energy in its atoms. The compound may, indeed, be compared to sodium oxide, and shares with that substance a capacity to unite with water, most energetically, and with great increase of entropy. It is apparent that the oxide cannot possibly be formed from pinacone under the conditions of the reaction, but, if a rearrangement may lead to the formation of an intramolecularly well neutralized substance, this may be formed, provided the increase of entropy due to the intramolecular neutralization is greater than the decrease that is due to the chemical hindrance, $i . e_{\text {, }}$, the energy necessary to effect the migration of a methyl group. These conditions are possible, for pinacoline represents a fairly well neutralized structure and has, consequently, a considerable heat of formation; ${ }^{1}$ and the expenditure of energy accompanying the migration of a methyl in pinacone is comparatively small, owing to the decrease of the affinity of carbon for carbon by the influsnce of the numerous hydrogens.

That phenyl exerts an extremely strong positive influence on any atom joined directly to $\mathrm{it}^{2}$ is evident from the fact that two such groups united directly with iodine, give that non-metal a metallic character. It might, therefore, have been expected, that the accumulation of phenyl groups would facilitate rearrangements of the nature of the pinacone $\rightarrow$ pinacoline reaction, as this has been especially proven by the investigations of Tiffeneau. We have, moreover, direct experimental evidence that hydrogen diminishes the affinity of carbon for carbon in the observation of Acree, ${ }^{3}$ that in the rearrangement with di-p-tolyldiphenylpinacone it is the more positive tolyl radical that migrates.

Another interesting illustration of this influence of hydrogen is found in that much-discussed substance "triphenylmethyl" (hexaphenylethane). Tshitshibabin ${ }^{4}$ has shown that replacement of five of the hydrogens in ethane by phenyl groups materially lessens the affinity of the ethane carbon atoms for each other. It is, therefore, not surpris-

1 Zoubuff, Chem. Centralbl., 99, I, 516.

2 Michael and Leighton, Ber., 39, 2792.

'Am. Chem. J., 33, I80.

4 Ber., 40, 367 . 
ing that when the remaining hydrogen is likewise replaced, the mutual affinity of these carbons is so greatly diminished that the substance easily dissociates into two molecules of triphenylmethyl, ${ }^{1}$ and that these carbons, or the carbon, in "triphenylmethyl" joined to the three phenyl groups, have chemical properties similar to those of a very positive metal, for instance, sodium. ${ }^{2}$ Nor is it surprising that hexaphenylethane may undergo easily a desmotropic rearrangement into the quinoid form:

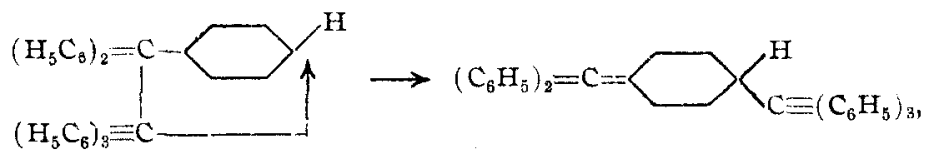

or, since the difference in the entropy values of these two forms is slight, that the existence of one or the other form, or a derivative, will depend on the nature of a reagent or even of a solvent. ${ }^{3}$

The remaining fundamental properties of carbon, its high valency and its capability to combine not only with hydrogen but with most of the non-metals to form stable derivatives, are also related to the position of the element in the periodic system. An element acts as monovalent towards $\mathrm{H}$, or $\mathrm{Cl}$, when its energy suffices to neutralize that of $\mathrm{H}$, or $\mathrm{Cl}$, to an extent that the system is incapable of uniting with further

${ }^{1}$ Since the above was written Schlenk $(A n n, 372, I)$ has shown that with a more positive radical than phenyl, $i . e$, , biphenyl, the affinity of carbon for carbon is reduced to such an extent that tribiphenylmethyl exists in solution in mono-molecular condition, which is a further confirmation of the above explanation.

2 Michael, J. prakt. Chem., [2] 60, 423, 428; 64, 107; Ber., 39, 279 I.

${ }^{3}$ Michael and Hibbert, Ber., 4I, rogI. A thermochemical investigation on intramolecular rearrangement will be published later; it may be stated that all our present experimental data on this subject confirm the view that the fundamental reason of the phenomenon is the increase of entropy proceeding with the change. In intramolecular changes it is the formation of an isomer with a greater heat of formation and in intermolecular rearrangements the increase of entropy is connected with a change in composition and the reagent uniting with a product of decomposition; in either case, slight chemical or physical forces may bring about the change, if the chemical hindrance is inconsiderable (see Michael and Hibbert, Ber., 4r, IOgI). The rearrangements of camphor on treatment with $\mathrm{P}_{4} \mathrm{O}_{5}$ and $\mathrm{H}_{2} \mathrm{SO}_{4}$, to which W. A. Noyes (This JournaL, 3I, 1372) recently called attention, may be understood from the point of view here presented. In camphor the affinity of the central carbon to those with which it is directly joined has been diminished considerably by the influence of hydrocarbon radicals and the central ring appears to exist in a condition of tension; moreover, such reduced benzene derivatives show a tendency to pass over into benzene derivatives, as the formation of the parabonds in benzene is connected with a considerable increase of entropy (Michael, $J$. prakt. Chem., [2] 79, 4I8). Phosphoric anhydride is a powerful dehydrating agent and the formation of a benzene derivative (cymene) with the elimination of water and rupture of a central carbon bond represents the maximum increase of entropy. In its action on camphor sulphuric acid acts not only as a hydrolyzing, but also as an oxidizing agent; the formation of p-acetyl-o-xylene undoubtedly represents the maximum entropy under such conditions. 
atoms of these elements. In passing from $\mathrm{F}$ to $\mathrm{O}$, from $\mathrm{O}$ to $\mathrm{N}$, and from $\mathrm{N}$ to $\mathrm{C}$, the valency for $\mathrm{H}$, or $\mathrm{Cl}$, increases, because the amount of energy in these atoms, able to neutralize that of $\mathrm{H}$, or $\mathrm{Cl}$, is successively decreasing. $\mathrm{CH}_{4}$ or $\mathrm{CCl}_{4}$ represent stable substances, because the energy and affinity relations between $\mathrm{C}$ and $\mathrm{H}$, or $\mathrm{Cl}$, are such that, in the combination of four atoms of hydrogen or chlorine among themselves and with one atom of carbon, comparatively little free chemical energy remains in any of the atoms. ${ }^{1}$

Like the polymerizing capacity and the "chemical plasticity" of carbon, its power to unite not only with hydrogen, but with most nonmetals, is due to the approximate balance of the positive and negative corpuscular energies in its atom. The direction in which the affinity of carbon for such elements will vary under the influence of other atoms in the molecule must be toward those of elements adjacent to it in the periodic system. Thus, the effect of increasing the influence of $\mathrm{H}$ on $\mathrm{C}$ in relation to $H$, or to a non-metal, joined to it, must be to shift its affinity values toward those of silicon, $i$. e., there should be a decrease in the value for $\mathrm{H}$ and an increase for that of a non-metal. On the other hand, increasing the influence of $O$ should shift them towards those of $N, i . e$, decrease the values both for $\mathrm{H}$ and a non-metal. Further, the effect of such changes on the content of free chemical energy of $\mathrm{C}$, and of any atom joined to it, must stand in a direct relation to the changes in the affinity values; in fact, the free must respond to such changes before the bound chemical energy.

According to van't Hoff, ${ }^{2}$ two atoms in a molecule acting through direct union or through space, or indirectly, that is through intermediate atoms. This idea has been further developed ${ }^{3}$ and shown to be of great importance in explaining organic reactions. If we number a certain atom in any fatty compound with a normal carbon chain by the figure $r$, our present knowledge of the combined mutual influence between this atom and others in the molecule is expressed by the following "scale of combined influence," the numbers indicating the degree of removal and the extent of the influence decreasing in the order given: $2-3-5-6-4-7-$

${ }^{1}$ Replacement of an $\mathrm{H}$ in $\mathrm{CH}_{4}$ by $\mathrm{Na}$ gives a substance with preponderance of positive energy, and which is, therefore, poorly neutralized intramolecularly. Carbon, a weak non-metal, in uniting with very positive metals, tends to form compounds of the type $\mathrm{C}_{2} \mathrm{Me}$, in which the accumulated negative energy of several carbon atoms endeavors to neutralize the positive energy of the metal. Only with a weak positive metal like $\mathrm{Al}$ are metallic derivatives of methane formed, and it is doubtless owing to this relation between the energies of $\mathrm{C}$ and $\mathrm{Al}$, the compounds of which are so widely distributed in nature, that we owe the occurrence of such enormous deposits of saturated hydrocarbons.

Ansichten üeber die organische Chemie, I, 284-285; II, 252-254.

${ }^{3}$ Michael, J. prakt. Chem., [2] 60, 331. Ber., 39, $2138-2157,2780-2790 ; 40$, 141. 
(9-10-II)-8. It is to be strongly emphasized that the effect of an atom in position 2 or 3 is far greater than that of any similar atom less closely connected, and, in the case of atoms farther removed, the influence must be largely direct, $i$. e., spatial.

The principles developed above form a new basis for the theory of organic chemistry and may be applied to any problem arising in the science.

Several important organic questions will be discussed from the new point of view. One of the weakest sides of the present structure theory is that it indicates the existence of a countless number of compounds, which are incapable of existence. One instance, that of an isomeric chloride of cyanogen (CINC) has been already discussed, but this question is of such importance that it will be considered with substances of a different type. Nitrosomethane $\left(\mathrm{H}_{3} \mathrm{CNO}\right)$ does not exist, as it passes over spontaneously into the isomeric oxime: $\mathrm{H}_{3} \mathrm{C}-\mathrm{NO} \rightarrow \mathrm{H}_{2} \mathrm{C}=$ $\mathrm{N}(\mathrm{OH})$. If we add an oxygen to the nitroso group, we obtain nitromethane $\left(\mathrm{H}_{3} \mathrm{CNO}_{2}\right)$, which is perfectly stable, but the tautomeric form of which $\left(\mathrm{H}_{2} \mathrm{C}=\mathrm{NO}(\mathrm{OH})\right)$ is so unstable, that its existence can be proven only by indirect means. The thermochemical equation, $2 \mathrm{NO}+\mathrm{O}_{2}=$ $2 \mathrm{NO}_{2}+26.9$ cal. proves conclusively that the nitroso group contains much more free chemical energy than the nitro, which is the reason why the nitroso group in nitrosobenzene is so much more reactive than the nitro group in nitrobenzene. In nitrosomethane, then, the following energetic and affinity relations exist: the oxygen has much free chem$i c a l$ energy and a strong affinity for the $\mathrm{H}$ of the methyl group, and by the change into the oxime, the great content of free chemical energy in the nitroso group is largely converted into bound chemical energy and heat. The transformation therefore proceeds with increase of entropy and the oxime represents an intramolecularly well neutralized structure, which agrees with its amphoteric properties and the slight additive capacity at the double bond. Since the nitro group in nitromethane has less free chemical energy than the nitroso in nitrosomethane, its oxygen has less capability to overcome the bound chemical energy holding the hydrogen to the carbon. A rearrangement to isonitromethane is barred for a second reason, viz., that it would proceed with a degradation of entropy, for it is evident that the neutral nitromethane, the nitro group of which carries but little free chemical energy, is vastly poorer in such energy than the strongly acidic, unstaturated isonitromethane. ${ }^{1}$

In order that a rearrangement should proceed spontaneously, the atom which receives the migrating atom, or group, must have sufficient affinity for it to be able to overcome the bound chemical energy between the migrating atom, or group, and the atom to which it is already joined.

1 See $A n n ., 363,21$. 
If we increase through a structural change the bound chemical energy more than we do the affinity and free chemical energy factor; or if we decrease the latter without essentially altering the former, we obviously increase the relative stability of the new derivative and it may show an existence in a free state. Through certain structural changes the difference between the entropy values of the isomeric forms may be lessened, and we may arrive in this way to desmotropic substances, the energy relations of which are so evenly balanced that the existence of one or the other form may be determined by a slight expenditure of extraneous chemical, or physical energy. ${ }^{1}$

Before 1887 the substitution process in organic chemistry was universally supposed to consist of the direct replacement of an atom, or group, by another. It was then shown, by an investigation on the constitution of acetoacetic ester and its sodium derivative, ${ }^{2}$ that this view could be upheld no longer and that apparent substitution is often the result of a combination of an addition and elimination process. Subsequent researches ${ }^{3}$ have shown that substitution, as represented by the old view is of comparatively rare occurrence, and that a rational interpretation of the process may be based on the entropy principle. Thus, by the use of a metal like sodium, which has considerable free chemical energy and a strong affinity for oxygen, the hydrogen in $\mathrm{CH}_{2}=\mathrm{NOH}$ attached directly to oxygen may be driven out, with the formation of $\mathrm{CH}_{2}=\mathrm{NONa}{ }^{4}$ This change is only apparently a direct replacement of hydrogen by sodium, for what actually occurs is, that the energy and affinity values of the metal are such that it is able to overcome the bound chemical energy between the oxygen and hydrogen and that the latter element is driven out, not replaced.

The distinction between replacing and driving out may seem from the above instance to be unimportant, but it is in reality of fundamental importance in organic reactions. Let us consider, for instance, the behavior of nitromethane and hydrocyanic acid towards sodium from the new point of view! In the system

2 Michael, Ann., 363, 27.

2 Michael, J. prakt. Chem. [2], 37, 473.

${ }^{3}$ Michael, Loc. cit., 60, 316. Ber., 33, 3739; 34, 4028; 38, 22, 1922-1938, 2083, 2097, 3218. Amer. Chem. J., 43, 330.

- It does not follow from the formation of this sodium derivative that the change as represented by $\mathrm{CH}_{2}=\mathrm{NOH} \longrightarrow \mathrm{CH}_{2}=\mathrm{NONa}$ designates an increase of entropy; indeed, a consideration of the well neutralized, amphoteric character of the oxime and the strong basic, easily hydrolyzed character of the sodium derivative, leaves no doubt that the free chemical energy in the latter is much greater than in the former structure. In the reaction much of the free chemical energy in sodium is converted into bound; it is the total change $\left(2 \mathrm{CH}_{2}=\mathrm{NOH}+\mathrm{Na}_{2}={ }_{2} \mathrm{CH}_{2}=\mathrm{NONa}+\mathrm{H}_{2}\right)$ that proceeds with increase of entropy. 


$$
\mathrm{H}_{3} \mathrm{C}-\mathrm{N}<\underset{\mathrm{O}}{\mathrm{O}}+\mathrm{Na}
$$

the metal may be attracted either by the $\mathrm{C}$ or the $\mathrm{O}$, but not only is the free chemical energy in the $O$ larger than that in the $C$, but also the chemical affinity for $\mathrm{Na}$. Moreover, according to the law of entropy, the system must strive to realize the maximum condition, which will be the formation of a sodium derivative, in which the free chemical energy existing in nitromethane and in sodium is converted as completely as possible into bound chemical energy and heat. This condition is realized by the direct union of $\mathrm{Na}$ with $\mathrm{O}$, since then an almost neutral salt will be formed, while the derivative containing the metal joined directly to $\mathrm{C}$ would be strongly basic and have positive energy in great excess. Indeed, if such a derivative as $\mathrm{NaCH}_{2} \mathrm{NO}_{2}$ could be obtained at a low temperature, it would pass over at ordinary temperature spontaneously and with an enormous increase of entropy into $\mathrm{CH}_{2}=\mathrm{N}(\mathrm{ONa}) \mathrm{O}^{1}$ The intramolecular hindrance, which nitromethane offers to attack, of the $\mathrm{Na}$ on the $\mathrm{O}$ is the energy necessary to overcome the bound chemical energy between a hydrogen and the carbon, which, owing to the strong negative character of the nitro group, is very considerably less than in methane and the reaction therefore proceeds readily.

According to the old substitution theory, the action of $\mathrm{Na}$ on $\mathrm{HCN}^{2}$ proceeds by the direct replacement of the hydrogen by the metal, forming $\mathrm{NaCN}$; according to the new theory, the $\mathrm{Na}$ may be attracted by the $\mathrm{C}$ or the $\mathrm{N}$, and a salt may be formed if the metal is able to overcome the bound chemical energy between the $\mathrm{H}$ and the $\mathrm{C}$ and the reaction proceeds with an increase of entropy. The properties of the cyano group leave no doubt as to the existence of considerable free chemical energy in the $\mathrm{C}$ and the $\mathrm{N}$, and there is also no doubt that $\mathrm{Na}$ has a greater affinity for $\mathrm{N}$ than for $\mathrm{C}$ : furthermore, $\mathrm{N}$, being an element with more negative chemical energy than $\mathrm{C}$, the energy of the metal in NaNC is much better neutralized than it would be in $\mathrm{NaCN}$. The energy and affinity conditions permit, therefore, in the direct formation of $\mathrm{CH}_{2}=\mathrm{NO}(\mathrm{ONa})$ and $\mathrm{NaNC}$, the maximum possible increase of entropy, and any other conception of the structures of these salts, is as inconceivable from the new theory, as the older view leaves us wholly in the dark in regard to them.

1 Although a "double" bond is usually an indication of the accumulation of free chemical energy, its symbolistic use for this purpose would be misleading. The free chemical energy in an atom must vary with the extent of intramolecular neutralization; i. $\varepsilon$, in $\mathrm{CH}_{2}=\mathrm{NO}(\mathrm{ONa})$ the free chemical energy at $\mathrm{C}$ and $\mathrm{N}$ is used up indirectly to a very considerable extent in neutralizing the positive energy of the sodium. An approximate idea of the free chemical energy in the atoms of a molecule can usually be formed by a consideration of their chemical nature, the structure and the properties of the substance.

${ }^{2}$ Michael and Hibbert, Ann., 364, 64 . 
We have seen that the positive energy in sodium has been largely converted into bound chemical energy, when the metal is introduced into nitromethane and that neither at the unsaturated carbon or nitrogen of $\mathrm{H}_{2} \mathrm{C}=\mathrm{N}(\mathrm{ONa}) \mathrm{O}$ is there much free chemical energy. It follows from these energy conditions that this salt should not easily react with a reagent, unless the latter contains atoms with much free chemical energy and a large affinity value for certain atoms in the salt. Hence, sodium isonitromethane is comparatively inert toward methyl iodide: but, if we make a change in the structure of the salt, so that the metal is less well neutralized, we shall facilitate the reaction; for, by doing so, we increase not only the free chemical energy of the unsaturated atoms, but the difference between the heats of formation of sodium iodide and the sodium salt, which is one of the largest factors in determining the entropy of the reaction. The conditions for an easy reaction are fulfilled, for instance, in sodium acetoacetic ester $\left(\mathrm{CH}_{3}-\mathrm{CONa}=\mathrm{CH}-\mathrm{COOC}_{2} \mathrm{H}_{5}\right)$, for in this derivative the positive energy of the metal is very inadequately neutralized by the weakly acidic organic radical to which it is joined, and the unequal balance between the positive and negative chemical forces must leave considerable free chemical energy in the unsaturated atoms. The reaction may proceed in two directions:

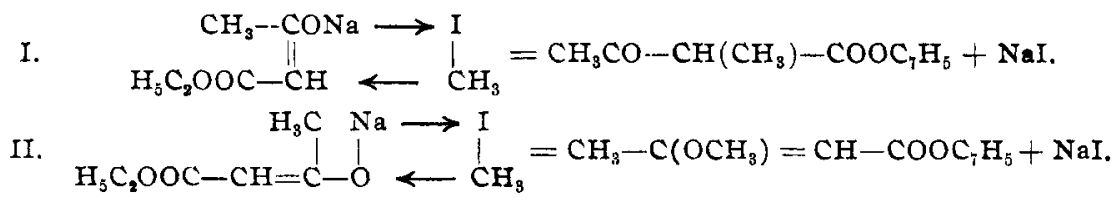

It is of interest to analyze the energy and affinity relations of the unsaturated carbon joined directly to the carbethoxyl group and those of the oxygen joined to sodium, since they determine the course of the reaction. Sodium iodide is formed in either case, and, as the heat of formation of the $\mathrm{C}$ - is greater than that of the $\mathrm{O}$-methyl derivative, ${ }^{1}$ its formation represents the maximum entropy of the system. The introduction of sodium into acetoacetic ester $\left(\mathrm{CH}_{3}-\mathrm{CO}-\mathrm{CH}_{2}-\mathrm{COOC}_{2} \mathrm{H}_{5}\right)$ has the following effect on the energy and affinity relations of the carbonyl oxygen (in $\mathrm{CO}$ ) and the methylene carbon (in $\mathrm{CH}_{2}$ ):

First, the free chemical energy in the $O$ has been greatly decreased through direct union with the metal, while part of the bound chemical energy of the $\mathrm{C}$ (used before in holding the eliminated $\mathrm{H}$ ) has been converted into free; second, the affinity of the $\mathrm{O}$ for $\mathrm{CH}_{3}$ has been greatly reduced by the positive influence of the metal, which, on the other hand, has neutralized the effect of the two negative radicals $\left(\mathrm{CH}_{8} \mathrm{CO}\right.$ and $\mathrm{COOC}_{2} \mathrm{H}_{5}$ ) and given the unsaturated $\alpha$ - $\mathrm{C}$ a large affinity value for methyl. It is evident that when we take the entropy, energy and affinity relations

1 Experimental proof will be published later. 
into consideration, the conversion of the $\mathrm{O}$-sodium salt into the $\mathrm{C}$-methyl derivative, $i$. $e$, the reaction represented by $I$, is not an abnormal, but a perfectly normal, reaction, ${ }^{1}$ as, indeed is every chemical change in which the condition of maximum entropy is realized.

Finally, we shall discuss another fundamental organic process, that of addition, from the standpoint of the second law of thermodynamics.

If we remove one hydrogen from two adjacent hydrocarbon groups in propane a compound is formed $\left(\mathrm{CH}_{3}-\mathrm{CH}=\mathrm{CH}_{2}\right)$ in which part of the bound chemical energy previously holding the eliminated hydrogen atoms in chemical union appears as free chemical energy at the unsaturated C-atoms. ${ }^{2}$ In the addition of a reagent to such a compound, the free chemical energy of the unsaturated atoms is more or less completely converted into bound chemical energy and heat, and the second law of thermodynamics compels the addition to take place in such a manner that the maximum entropy will be realizcd, unless there is some chemical hindrance, which prevents this attainment of the ultimate goal of free chemical energy.

The structure theory teaches us that in the addition of hydrobromic acid to propene, two isomers (propyl and isopropyl bromide) may be formed, but it fails altogether to give us any indication which of these products, or whether both of them, should result. The chemical hindrance in this reaction is the energy necessary to overcome the bound chemical energy between the $\mathrm{H}$ and the $\mathrm{Br}$ of $\mathrm{HBr}$ to the extent to which it exists between them in the bromopropane that will be formed in the addition. ${ }^{3}$ This hindrance is obviously quantitatively the same in the formation of either isomer. The maximum entropy in this addition will be attained, therefore, in the formation of the isomeric bromopropane with the greater heat of formation.

Obviously, it is of great importance in this and in many other organic reactions to be able to trace the relation between the structure of isomers and their heat of formation. This is enabled by the following "thermochemical law of structure." In isomers with normal chains and which contain a common negative radical as a nucleus, that isomer will have the largest heat of formation, the positive radicals of which to the greatest extent are under the influence-direct and indirect-of the negative nucleus. Thus, in propyl and isopropyl bromide the common negative nucleus is $\mathrm{CBr}$, which in the last compound is under the direct influence of two methyl groups, while in propyl bromide only one methyl is directly, the other indirectly, joined. The intramolecular neutraliza-

'Michael, Ber., 38, 129.

2 J. prakt. Chem., [2] 60, 298.

${ }^{3}$ Michael, Am. Chem. J., 43, 333 (footnote).

4 Michael, J. prakt. Chem., [2] 68, 499; 79, 4I8; Ber., 39, 2 I 4 O. 
tion, which finds an expression in the heat of formation, is therefore larger in the iso than in the normal bromide, and, since the thermic value of direct is very much greater than that of indirect chemical union, the heat of formation of the former compound is considerably larger than that of the latter.

Not only does the system, propene and hydrobromic acid, realize its maximum condition of entropy in the formation of isopropyl bromide, but the affinity relations at the points of maximum concentration of the free chemical energy, i. e., at the unsaturated carbons, are such as to favor the course of the reaction in this direction, since the influence of methyl in this substance is positive to that of hydrogen in the same position. ${ }^{1}$ This relation causes in propene a greater accumulation of positive energy at the middle than at the end unsaturated carbon and the middle carbon must have, therefore, the greater affinity for the strongly negative halogen of the acid. It seems theoretically probable that this coincidence of affinity and entropy values should lead exclusively to the formation of the iso derivative, as, indeed, it would if chemical change depended solely on the free energy and the affinity values. When a mixture, containing an acid with a very large and a very small acidity constant, is brought together with a quantity of a strong base inadequate for complete neutralization of the acids present, there is always an appreciable amount of salt derived from the weak acid formed. The chemical force in each acid endeavors to its utmost capacity to contribute its share toward the increase of entropy, which depends not only on the values of the affinity constants but, although to a very much smaller degree, on the actual mass, by weight, of acid present.

If the formation of normal propyl bromide from propene and hydrobromic acid proceeds with an increase of entropy, which it undoubtedly does, we have in this addition reaction two chemical forces, each striving to increase the entropy, but, in this case, the mass by weight cannot be changed and the struggle is between energies. ${ }^{2}$ Furthermore, since there is no difference in the chemical hindrance to the addition in either direction, it is extremely probable that the relative amounts of salts, or isomeric bromides, formed will stand in a direct relation to the increase of entropy, and as this is very much greater with the formation of isopropyl bromide, it agrees with the theory that the normal bromide is formed only to a very slight extent. ${ }^{3}$

The principle here involved was first used by Thomson ${ }^{4}$ to determine the relative acidity constants, and has been called the "principle of

${ }^{1}$ Michael, J. prakt. Chem., [2] 60, 332; Ber., 39, 2 I42 (footnote).

2 There is no practical difference, as matter from a chemical point of view should be considered only as a carrier of chemical energy.

${ }^{3}$ Michael and Leighton, $J$. prakt. Chem., 60, 443.

${ }^{4}$ Pogg. Ann., r38, 497. 
partition"; it may be applied to every organic reaction where two or more isomers may be formed. ${ }^{2}$ Let us take, as illustrations of the application of this principle, the addition of water by means of sulphuric acid to hexine- $\mathrm{I}$ and -2 . In hexine- $\mathrm{I}\left(\mathrm{CH}_{3}-\mathrm{CH}_{2}-\mathrm{CH}_{2}-\mathrm{CH}_{2}-\mathrm{C} \equiv \mathrm{CH}\right)$, we have practically the same conditions as in propene, that is, the difference between the energy and affinity values of the unsaturated carbons are due to the difference between the direct influence of an alkyl group and a hydrogen; hexanone-2 $\left(\mathrm{CH}_{3}-\mathrm{CH}_{2}-\mathrm{CH}_{2}-\mathrm{CH}_{2}-\mathrm{CO}-\mathrm{CH}_{3}\right)$ and probably a very slight amount of hexanal $\left(\mathrm{CH}_{3}-\mathrm{CH}_{2}-\mathrm{CH}_{2}-\mathrm{CH}_{2}-\right.$ $\left.\mathrm{CH}_{2}-\mathrm{CHO}\right)$ are formed. The relations in hexine-2 $\left(\mathrm{CH}_{3}-\mathrm{CH}_{2}-\mathrm{CH}_{2}-\right.$ $\mathrm{C} \equiv \mathrm{C}-\mathrm{CH}_{3}$ ) are quite different; the unsaturated carbons are both joined directly to alkyl groups, and the change in their energy values is due not to direct, but to indirect, influences, which are largely spatial. This relation must cause the heats of formation of the products that may result, hexanone-2 and -3 , to be much nearer together than the isomers that may be formed in the addition to hexine-I; also an approximation in the energy and affinity values at the unsaturated carbons.

According to the "principle of partition," the relative amounts of hexanone-2 and -3 formed should not fall very far apart. Moreover, we can approximately estimate the energy values of the unsaturated carbons in relative terms by the use of the "scale of combined influence" mentioned above. Applying this scale to the relations in hexine-2, omitting those atoms the influences of which on the unsaturated carbons are equal, ${ }^{2}$ or very nearly so, we find that $\Delta^{\beta}-C^{3}$ (joined directly to methyl) is under the influence of one carbon in the 4 th, one hydrogen in the $3 \mathrm{rd}$, and three hydrogens in the 5 th position, and $\Delta^{r}-\mathrm{C}$ (joined directly to butyl) has one carbon acting in the 3 rd and 4 hydrogens in the $4^{\text {th }}$ position. Since atoms in the 3 rd and $5^{\text {th }}$ positions exert a greater influence than those in the $4^{\text {th }}$, it is obvious that the positive energy at $\Delta^{\beta}-\mathrm{C}$ is greater than that at $\Delta^{\gamma}-\mathrm{C}$, and that a larger proportion of that ketone should be formed, when the negative part of the addenda adds to it, $i$. e., hexanone-2. A re-investigation ${ }^{4}$ of the reaction shows indeed that about 60 per cent. of hexanone- 2 to 40 per cent. of -3 are formed in the reaction.

The present structure theory has been, and always will be, of inestimable service to organic chemistry: it has taught us, until recently, ${ }^{5}$ the possible number of isomers that may exist of a given formula, and it has been a guide in determining the constitution of most of the substances that

'Michael, J. prakt. Chem., [2] 60, 341-354; Ber., 39, 2138-2156, 2569, 27862795; 40, 140 .

${ }^{2}$ See J. prakt. Chem., 60, 341. Ber., 39, $214 \mathrm{r}$.

'The capital "Delta" denotes unsaturation (Baeyer, Ann., 245, 112).

4 Michael, Ber., 39, 2 I33.

${ }^{5}$ Ber., 39, 203. 
have been discovered. But its weakness and limitations are inherent in its foundation on a mechanical conception of valency and an almost exclusive theoretical development along similar lines, for surely in nature there are no forces more intimately and indissolubly connected with changes in energy than the chemical.

Largely for this reason, the structure theory fails to offer explanations for many of the simplest organic reactions and, for many years, it has failed in explaining and co-ordinating with theory much of the wonderful experimental progress that has been made in the science.

It is true that innumerable attempts have been made to amplify or change the idea of valency and the structure theory so as to remedy these deficiencies, but they have always been along mechanical lines and have led to such impossible theoretical conceptions as new brands of valencies, dissociated and partial valencies, oxonium and carbonium theories, steric hindrance due to size of the atoms, etc., etc.

All the forces in nature, whether mechanical or chemical, have the same goal in view, which is the realization of the maximum condition of entropy, and a scientific theory of chemistry must inevitably have this law as its basis. The present aim of organic theory is not to abandon the structure theory, but so to broaden and develop it that it becomes a consistent and harmonious part of nature.

Newton Centre, Mass.

\section{NEW BOOKS.}

The Elements of the Science of Nutrition. By GraHAM Lusk, Ph.D., M.A., F.R.S., (Edin). Second edition. W. B. Saunders Company: Philadelphia, I910. 402 pages, illustrated. Cloth, $\$ 3.00$ net.

The science of nutrition attracts attention at the present time from the physiologist, the chemist and the practicing physician, but whatever his interest may be, the man who wishes to follow the developments of that science of to-day must have at his command a good knowledge of modern physiological chemistry. This truth is well illustrated in the book in question.

The science of nutrition, like many other sciences, goes back to Lavoisier for its beginning, and in an interesting introductory chapter Lusk traces the cardinal points in its growth down to the present time. The author is a well-known physiologist and has himself made valuable contributions to the field. He has condensed into some four hundred pages a very clear and interesting résumé of the noteworthy literature of the subject. The book is divided into fifteen chapters which discuss the uses and effects of various kinds of foods, the relations to temperature and to work, the products of metabolism and other questions which properly belong in such discussions The treatment is much fuller and more satisfactory than is usually found in works on physiology which, in a way, cover the 